\title{
Cálculo no Ensino Médio: Uma abordagem possível e necessária com auxílio do Software GeoGebra
}

\author{
Calculus in high school: approach possible and necessary with \\ the aid of Software GeoGebra
}

\begin{abstract}
Ms. Jaqueline Molon ${ }^{1}$ e Dr. Edson Sidney Figueiredo ${ }^{2}$
${ }^{1}$ Mestre em Matemática, Professora do instituto Federal de Educação, Ciência e Tecnologia do Rio Grande do Sul - Campus Canoas - profejaquemolon@gmail.com

${ }^{2}$ Professor Doutor do Centro de Ciências Naturais e Exatas - Universidade Federal de Santa Maria UFSM
\end{abstract}

\begin{abstract}
Resumo
Este artigo é fruto da dissertação do Mestrado Profissional em Matemática em Rede Nacional, defendida em março de 2013 na Universidade Federal de Santa Maria (UFSM). O trabalho teve como objetivo principal verificar a possibilidade da inserção, no Ensino Médio, das ideias intuitivas do Cálculo Diferencial e Integral: limites de função, taxa de variação média, taxa de variação instantânea e o cálculo de áreas abaixo do gráfico de funções positivas, limitadas pelo eixo das abscissas e por retas verticais, ou até mesmo entre funções positivas em um intervalo determinado pelo domínio das mesmas. Para facilitar o entendimento dessas ideias, foram desenvolvidas atividades utilizando o Software GeoGebra como ferramenta de apoio a aprendizagem. As atividades foram aplicadas a uma turma experimental de alunos do primeiro ano do Ensino Médio, aliado ao estudo de funções quadráticas. Verificou-se que é possível abrir os horizontes no âmbito do ensino e aprendizagem de Matemática no Ensino Médio, para as ideias intuitivas do Cálculo. Neste trabalho serão apresentados os objetivos dessa pesquisa, algumas atividades propostas e os resultados alcançados, bem como propor desdobramentos para aprofundar e aplicar os assuntos aqui abordados.
\end{abstract}

Palavras-chave: Cálculo no Ensino Médio, Funções Quadráticas, Software GeoGebra.

\begin{abstract}
This article is the result of the dissertation of the Professional Masters in Mathematics in National Network, held in March 2013 at the Federal University of Santa Maria (UFSM). The work aimed to verify the possibility of inclusion in high school, the intuitive ideas of the Differential and Integral Calculus: limits of a function, the average rate of change, instantaneous variation and calculation of areas under the graph of positive functions, limited the $x$-axis and vertical lines, or even between positive functions in a particular area of the same range. To facilitate the understanding of these ideas, activities were developed using the Software GeoGebra as support learning tool. The activities were applied to an experimental group of students from the first year of High School, combined with the study of quadratic functions. It was found that you can open the horizons within the teaching and learning of mathematics in high school, to the intuitive ideas of calculus. In this work, the objectives of this research will be presented, some proposed activities and the results achieved, and propose developments to deepen and apply the issues discussed here.
\end{abstract}

Keywords: Calculus in High-School, Quadratic functions, Software GeoGebra. 


\section{Introdução}

O ensino e aprendizagem de Matemática em todos os níveis de escolaridade, desde o Ensino Fundamental ao Ensino Superior, tem sido foco de diversos estudos. Os alunos frequentemente apresentam dificuldades na compreensão de conceitos matemáticos. Muitos deles não encontram sentido ou aplicação dos conteúdos abordados em sala de aula. Essas dificuldades não se limitam apenas aos conceitos básicos, uma vez que os conteúdos dessa disciplina se encadeiam e é necessária a compreensão de uns para o aprendizado dos assuntos seguintes.

Diversos estudos apontam para a necessidade de uma mudança, principalmente no que diz respeito à linguagem matemática, como destaca Ávila (1993, p.3): “a linguagem não motiva ninguém, ideias sim. Nenhum aluno pode se interessar por qualquer coisa onde não veja algum elemento que lhe satisfaça ou aguce a curiosidade". No Ensino Médio ocupa-se praticamente todo o primeiro ano com formalismos da teoria dos conjuntos, definições de funções injetoras, bijetoras e sobrejetoras, deixando de lado um ponto muito interessante que se pode apresentar aos alunos: a aplicação de cada função, a visualização do comportamento de cada gráfico, entre outros aspectos.

Um ensino de funções que não enfatiza a aplicação e a visualização, pode refletir nas dificuldades que se apresentam atualmente nas disciplinas iniciais de Cálculo nos mais diferentes cursos superiores nas áreas de ciências exatas e de tecnologia. Estudos e pesquisas têm apontado que há um grande número de não aprovações nas disciplinas iniciais de Cálculo dos cursos superiores no Brasil que envolvam conteúdos relacionados, principalmente, ao estudo de funções, ou seja, conceitos de limites, derivadas e integrais. Segundo Rezende (2003, p.1) um dos grandes desafios no Ensino Superior de matemática é o "fracasso no ensino de Cálculo". Para este autor, a origem histórica desse "fracasso" acontece ainda no momento em que se começa a ensinar Cálculo.

Embasado nesses fatos, a dissertação de mestrado que dá origem a este artigo, se propôs a analisar a inserção das ideias intuitivas do Cálculo Diferencial e Integral no Ensino Médio, através de atividades de visualização e experimentação, utilizando como recurso computacional o software GeoGebra.

\section{Dificuldades encontradas no Ensino de Cálculo no Ensino Superior}

As dificuldades no ensino de Cálculo e o grande número de não aprovações nessa disciplina e em outras relacionadas no Ensino Superior, já foram citados na introdução deste trabalho. Para ilustrar esta situação foi realizado um levantamento dos índices de não aprovação nas disciplinas de cursos oferecidos por universidades brasileiras. 
Para exemplificar, destaca-se Rezende (2003, p.1) que cita várias instituições de ensino que apresentam resultados não muito satisfatórios no estudo desses tópicos de matemática. Baruffi (1999 apud REZENDE, 2003, p. 1) relata que:

[...] o índice de não aprovação em cursos de Cálculo Diferencial e Integral oferecidos, por exemplo, aos alunos da Escola Politécnica da USP, no período de 1990 a 1995, varia de 20\% a 75\%"', enquanto que no universo dos alunos do Instituto de Matemática e Estatística o menor índice não é inferior a $45 \%$. (BARUFI, 1999 apud REZENDE , 2003, p.1).

Na sequência, Rezende (Ibid., p.2) destaca os índices relativos à UFF Universidade Federal Fluminense. Segundo ele, "a variação do índice de não aprovação se encontra na faixa de $45 \%$ a $95 \%$, sendo que para o Curso de Matemática este não é inferior a $65 \% "$. Essa situação não é particular de uma universidade ou outra, pois os índices também são semelhantes, por exemplo, na Universidade Federal de Santa Maria - UFSM, de acordo com os dados fornecidos pelo Departamento de Matemática dessa universidade.

Durante o trabalho foram levantadas as informações relativas a um período de três anos a contar do segundo semestre de 2009 ao primeiro semestre de 2012. As disciplinas analisadas foram: Cálculo I, Cálculo A, Cálculo Diferencial e Integral I, Cálculo I-A e Cálculo Infinitesimal I. Essas disciplinas possuem, em geral, a mesma ementa, porém são aplicadas a cursos diferentes na UFSM. A análise realizada buscou simplesmente avaliar quantitativamente as aprovações e não aprovações nas disciplinas citadas em cada semestre letivo.

No total foram analisadas 3457 matrículas. Desse total, 1447 alunos foram aprovados com nota, sendo que a maioria, ou seja, os demais 2010 estudantes, não obtiveram sucesso nessas disciplinas, sendo reprovados por nota ou por frequência ou, ainda, efetuaram trancamento parcial ou cancelamento de matrícula. $\mathrm{O}$ índice geral de não aprovação nesse período foi de $58,14 \%$.

Diante desses dados é possível perceber a necessidade de propor alternativas para superar esse problema. Uma delas é, portanto, a possibilidade da inserção das ideias de Cálculo no Ensino Médio. Atividades que envolvam as ideias intuitivas de limites, que explorem a questão da variabilidade através de problemas de aplicação e o cálculo da área de regiões demilitadas por curvas que são gráficos de funções, podem se mostrar, nesse sentido, bons caminhos para o trabalho significativo da matemática no Ensino Médio. Além disso, proporcionar aos estudantes a utilização de recursos gráficos, também pode contribuir para um melhor entendimento desses tópicos, auxiliando a promover a autonomia dos estudantes.

\section{Limites, derivadas e integrais no Ensino Médio?}

Você deve estar se perguntando: limites, derivadas e integrais são assuntos viáveis ao entendimento de um aluno do Ensino Médio? Se considerarmos o Cálculo com toda sua 
linguagem formal, simbólica, seus teoremas e demonstrações, definições e todo o seu rigor, a resposta a esse questionamento seria negativa, pois esses conteúdos repletos de detalhes, exigem conhecimentos específicos que ainda não são do domínio de um estudante nesta fase de sua escolaridade. No trabalho desenvolvido a proposta envolvia a simples, porém importante, introdução das ideias geradoras do Cálculo no Ensino Médio, abordando os aspectos intuitivos de cada tópico.

Baseados na história da matemática (ANTON, 2000, p.112) podese perceber que os problemas que motivaram as ideias básicas do cálculo são: o problema da Reta Tangente; o problema da Área; e o problema da Velocidade Instantânea.

No entanto, esses problemas apesar de parecerem distintos, possuem uma raiz comum: todos envolvem processos infinitos de aproximação. De acordo com Anton (2000, p.4, grifo do autor), pode-se notar que esses assuntos “estão intimamente ligados pelos princípios fundamentais do Cálculo e que todos eles envolvem de alguma forma, processos infinitos". Sendo assim, como relacionar esses temas geradores, aos conteúdos do Ensino Médio de forma a inserir as ideias intuitivas do Cálculo Diferencial e Integral?

Uma possibilidade é atentar ao estudo de funções (neste trabalho, o foco foi na função quadrática), durante a análise do seu comportamento gráfico, de modo a fazer com que o aluno compreenda, por exemplo, que os valores de uma função quadrática do tipo $f(x)=a x^{2}+b x+c$, para valores reais positivos de $a$ e valores quaisquer para " $b$ " e " $c$ ", tornam-se cada vez maiores, na medida em que tomamos valores do domínio dessa função cada vez maiores ou cada vez menores. De forma análoga, quando se considera valores reais negativos para o coeficiente " $a$ ", os valores da função quadrática se tornam cada vez menores na medida em que se tomam valores cada vez maiores ou menores para a variável independente $x$.

O problema da reta tangente, por sua vez, pode ser abordado a partir do conceito de reta secante ao gráfico de uma função, fazendo com que a reta secante se aproxime cada vez mais da posição tangente, na medida em que considerarmos intervalos cada vez menores no domínio dessa função. Destaca-se, porém, que mesmo que o aluno não conheça o significado de reta tangente (e no início do primeiro ano do Ensino Médio, provavelmente não conheça) é possível introduzir esse conceito através da visualização e da experimentação com atividades que façam com que uma reta secante "tenda" a posição tangente em ponto desejado do gráfico da função.

Esse processo também pode ser utilizado para introduzir a noção intuitiva de derivada de uma função em determinado ponto, através do cálculo do coeficiente angular da reta tangente ao gráfico da função no ponto desejado. A introdução desses conceitos pode ser acompanhada das aplicações da Física, e pode facilitar o entendimento dessa disciplina, como afirma Duclos (1992, p.28): "A Física é a base da técnica e a Matemática a linguagem da Física". Para Ávila (2006, p.37), essa afirmação se justifica uma vez que: "o ensino da 
derivada é da maior importância, pelo tanto que ajuda no tratamento de inúmeras propriedades das funções. E tem de ser feito logo na primeira série, quando pode integrar-se harmoniosamente com a Física no estudo do movimento".

Também aliado ao estudo de funções, é possível e natural, falar em taxas de variação. Nessa etapa, é possível falar sobre acréscimos e decréscimos nas variáveis envolvidas e apresentar aos estudantes a notação utilizada para indicar essa variação, $\Delta x$ ou $\Delta y$. Em seguida, é possível explorar o cálculo do coeficiente angular de uma reta utilizando a notação $\frac{\Delta y}{\Delta x}$. Notação essa que, provavelmente o aluno já tenha visto em seus estudos de Física e relacioná-la com a declividade da reta. Para esse processo de aprendizagem é importante trabalhar com diversos exemplos e problemas concretos, de modo a familiarizar o estudante com a utilização desses conceitos e notações.

O terceiro problema gerador das ideias fundamentais do cálculo é o da área. $\mathrm{O}$ aluno na primeira série do Ensino Médio, com seus conhecimentos geométricos, é capaz de calcular áreas de figuras planas regulares como retângulos, quadrados, triângulos, trapézios e círculos. Algo curioso, talvez desafiador, nessa etapa seria propor a esse aluno que efetuasse o cálculo de áreas de regiões irregulares, como por exemplo, regiões curvas limitadas pelo gráfico de uma função em um determinado intervalo.

Apesar disso, se o estudante já teve contato com a ideia de aproximação ao trabalhar com a noção intuitiva de limites, pode-se aproveitar esse fato e introduzir a ideia de aproximação da área desejada pela soma de áreas menores, constituídas por figuras geométricas já conhecidas. Na verdade, de acordo com Anton (2000), esse procedimento para o cálculo da área, remonta à história da matemática, uma vez que esse foi o processo adotado por Arquimedes (287 a.C. - 212 a.C.) que calculou corretamente a área sob uma parábola utilizando o método de exaustão. Nesse mesmo sentido, Simões (2012) escreve que Arquimedes preencheu a área que desejava calcular com um número crescente de triângulos e percebeu que a soma das áreas desses triângulos se aproximava cada vez mais de um valor na medida em que o número de triângulos aumentava.

A ideia intuitiva para o cálculo de áreas aplicado por Arquimedes é o processo que pode ser utilizado no Ensino Médio, o qual introduz o conceito de integral:

\footnotetext{
Para calcular a área sob o gráfico, podemos raciocinar da seguinte maneira: vamos subdividir o intervalo considerado em muitos pequenos intervalos, suficientemente pequenos [...]. Assim, em cada um dos pequenos intervalos, uma fatia da área que buscamos pode ser calculada como se fosse um pequeno retângulo; depois, para se ter a área procurada, basta somar as áreas de todos os retangulinhos. (MACHADO, 2008, p.3)
}

Na sequência desse texto o autor complementa: "Integrar é juntar esses pedaços" (Ibid., p.3). Utilizando o mesmo ponto de vista, a Revista Cálculo na reportagem especial "Cálculo sem pressa é bom", destaca, em uma 
linguagem informal, a ideia intuitiva do processo de integração:

Integração é isso: se o estudante precisa
achar a área de uma figura geométrica
cheia de curvas, ele fatia a figura,
substitui cada fatia por um retângulo
(isto é, substitui cada fatia por uma
figura cuja área é fácil de calcular), e
soma todas as fatias. Conforme o
número de fatias aumenta, a área de
todos os retângulos somados se
aproxima da área real; conforme o
número de fatias tende ao infinito, a área
de todos os retângulos somados tende à
área real exata. (SIMÕES, 2012, p.32)

Assim, através da visualização do gráfico de determinada função, é possível fazer com que os estudantes identifiquem a região a qual se deseja aproximar a área e efetuem o seu cálculo como indicado acima. Dessa forma intuitiva o conceito de integral pode ser trabalhado na educação básica de modo a ampliar os conhecimentos dos alunos em relação à aplicabilidade da matemática. Afinal, nos problemas reais envolvendo o cálculo da área de uma plantação, por exemplo, dificilmente a região considerada será exatamente uma figura geométrica regular, sendo que o processo de aproximação pode auxiliar nesse cálculo.

A partir das colocações acima, podemos retomar o questionamento inicial: limites, derivadas e integrais são assuntos viáveis ao entendimento de um aluno do Ensino Médio? Se considerarmos as ideias intuitivas, através dos problemas geradores desses conceitos do Cálculo Diferencial e Integral, como apresentados acima, acreditamos que a resposta seja afirmativa. Alguns estudantes poderão apresentar dúvidas, mas dificuldades em Matemática sempre existiram, e cabe ao professor propor esse desafio aos estudantes do Ensino Médio. Além disso, também é responsabilidade e dever do professor proporcionar aos estudantes diferentes alternativas para que alcance seus objetivos de aprendizagem, como por exemplo, com a utilização de um recurso computacional de visualização, que é o caso do software GeoGebra, proposto nesse trabalho.

\section{Desenvolvimento e metodologia}

As atividades propostas nesse trabalho foram planejadas para aplicação a uma turma experimental, composta por 14 estudantes, 6 meninas e 8 meninos, com idades entre 14 e 16 anos, do primeiro ano do Ensino Médio, identificados de ora em diante como $\mathrm{A}_{i}$, com $1 \leq \mathrm{i} \leq 14$.

Essa turma se reuniu durante cinco encontros com duração de quatro horas cada, no laboratório de informática da escola Francisco Zilli, no município de Flores da Cunha - RS. No primeiro encontro, os estudantes receberam as atividades selecionadas, divididas em quatro roteiros, bem como as orientações para o desenvolvimento de todo o trabalho.

De modo geral, cada roteiro continha todas as informações referentes à utilização do software GeoGebra para o desenvolvimento de cada atividade. Após a construção, que era solicitada aos estudantes, os objetos construídos eram manipulados e em seguida os alunos respondiam aos questionamentos relativos a cada atividade. 
Antes de iniciar a resolução das atividades, em cada tarde, os estudantes recebiam orientações sobre os objetivos daquele encontro e sobre o que se pretendia explorar com as atividades naquele momento, além de exemplos da aplicação dos conceitos que seriam explorados. Os estudantes trabalhavam, de forma geral, individualmente, mas, por vezes, conversavam com seus colegas para relembrar algum conceito já estudado.

Serão abordados neste artigo algumas das atividades aplicadas e os resultados alcançados, buscando confirmar nossa hipótese de que é possível explorar os conceitos intuitivos de limites, derivadas e integrais no Ensino Médio.

\section{Algumas atividades: muitos resultados}

\subsection{Roteiro de atividades 1}

O primeiro roteiro trazia três atividades com o objetivo de apresentar o software GeoGebra (versão 6.3) aos alunos e orientá-los para a utilização de suas principais funções, utilizando as janelas algébrica e gráfica e alguns dos recursos disponíveis nos botões da barra de ferramentas da tela inicial do programa. Aliado a esse intuito, pretendia-se também revisar as características principais dos gráficos das funções de $1^{\circ}$ e $2^{\circ}$ grau, como calcular e interpretar o coeficiente angular de uma reta e analisar a concavidade de uma função quadrática, $\boldsymbol{f}(\boldsymbol{x})=\boldsymbol{a} \boldsymbol{x}^{2}+\boldsymbol{b} \boldsymbol{x}+\boldsymbol{c}$, em relação ao parâmetro " $a$ ".
Nesta etapa, foram propostas questões de revisão e estudo das principais características de uma função quadrática. O trabalho seguiu com a exploração de um exemplo numérico, para posterior estudo de funções desse tipo, a partir de sua lei de formação geral utilizando os parâmetros " $a$ ", " $b$ " e " $c$ ", ou seja, $f(x)=a x^{2}+b x+c$, também utilizando o recurso "seletor" do software. $\mathrm{O}$ objetivo aqui era analisar a concavidade da função e os pontos de intersecção do seu gráfico com os eixos cartesianos conforme mostra a figura 1 .

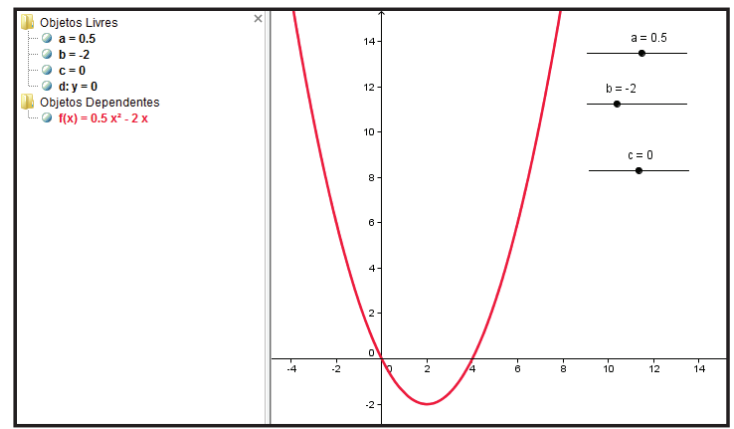

Figura 1 - Construção realizada pelo aluno $7\left(\mathrm{~A}_{7}\right)$.

Ao analisar as respostas dos alunos às perguntas elaboradas para explorar as mudanças no gráfico da função, provocadas pela alteração de cada um dos parâmetros " $a$ ", " $b$ " e " $c$ " adotados, os alunos conseguiram estabelecer as relações desejadas através da observação. No que se refere ao significado do parâmetro " $a$ " podemos destacar algumas respostas (que se repetiam) para as questões abaixo.

a) Mantendo fixos os parâmetros " $b$ " e " $c$ " e movimentando o parâmetro " $a$ ", o que acontece com o gráfico da função?

"Muda a concavidade da parábola para cima e para baixo". (A8) 
"Ocorre a alteração da concavidade (direção), para cima ou para baixo". ( $\left.\mathrm{A}_{2}\right)$

"Quando fica negativo a parábola é pra baixo e se é positiva a parábola é pra cima". $\left(\mathrm{A}_{14}\right)$

b) Mantendo fixos os parâmetros " $a$ " e " $c$ " e movimentando o parâmetro " $b$ ", o que acontece com o gráfico da função?

Nesse tópico, somente três alunos relacionaram corretamente o significado desse parâmetro, citando que o gráfico "se movimenta", mas que a intersecção com o eixo OY ocorre sempre no mesmo ponto, para cada valor do parâmetro " $c$ " que estava fixo. Os demais alunos citaram apenas que a parábola se movimentava, não citando como isso acontecia.

"O ponto de intercepção do eixo OY, está sempre no mesmo local" ( $\left.\mathrm{A}_{2}\right)$

"A parábola continua igual e apenas se desloca interceptando o eixo y em um mesmo ponto".(A5)

"Vai para os lados, mas nunca a parábola sai do 'c'"'. ( $\left.\mathrm{A}_{3}\right)$

c) Mantendo fixos os parâmetros " $a$ " e " $b$ " e movimentando o parâmetro " $c$ ", o que acontece com o gráfico da função?

Todos os alunos nessa questão relacionaram o parâmetro " $\mathrm{c}$ " com o deslocamento do gráfico na direção vertical, para cima ou para baixo, conforme destacamos algumas falas:

"Ele sobe e desce conforme o parâmetro "c" é movimentado".(A9)

"Ele muda sua posição na vertical, tornando o termo " $\mathrm{C}$ " positivo ou negativo". $\left(\mathrm{A}_{2}\right)$
"Muda a posição vertical do gráfico". ( $\left.\mathrm{A}_{4}\right)$

Com as atividades sugeridas nesta etapa do trabalho, foi possível introduzir algumas ferramentas e a sintaxe do software GeoGebra. Os estudantes puderam revisar o que já haviam aprendido sobre funções e aprofundar seus conhecimentos acerca das variações dos parâmetros envolvidos em cada lei de formação, a partir da visualização. Dessa forma, acredita-se que os objetivos estabelecidos para estas atividades tenham sido alcançados.

\subsection{Roteiro de atividades 2}

As atividades desenvolvidas pelos estudantes até a etapa anterior, apesar de utilizar alguns recursos diferentes em sua abordagem, exploravam conceitos que eles, de alguma forma já haviam tido contato através de seus estudos anteriores. No segundo roteiro, esta análise continuou, a fim de verificar se os estudantes poderiam construir um conceito fundamental em várias áreas da matemática: a ideia intuitiva de limite de uma função, especialmente aplicado à função quadrática.

A primeira atividade desse roteiro, orientava os estudantes para a construção do gráfico da função $f(x)=x^{2}$, destacando no GeoGebra com a opção "Habilitar rastro" o domínio e a imagem dessa função, como pode-se verificar na construção feita pelo aluno A7 na figura 2. 


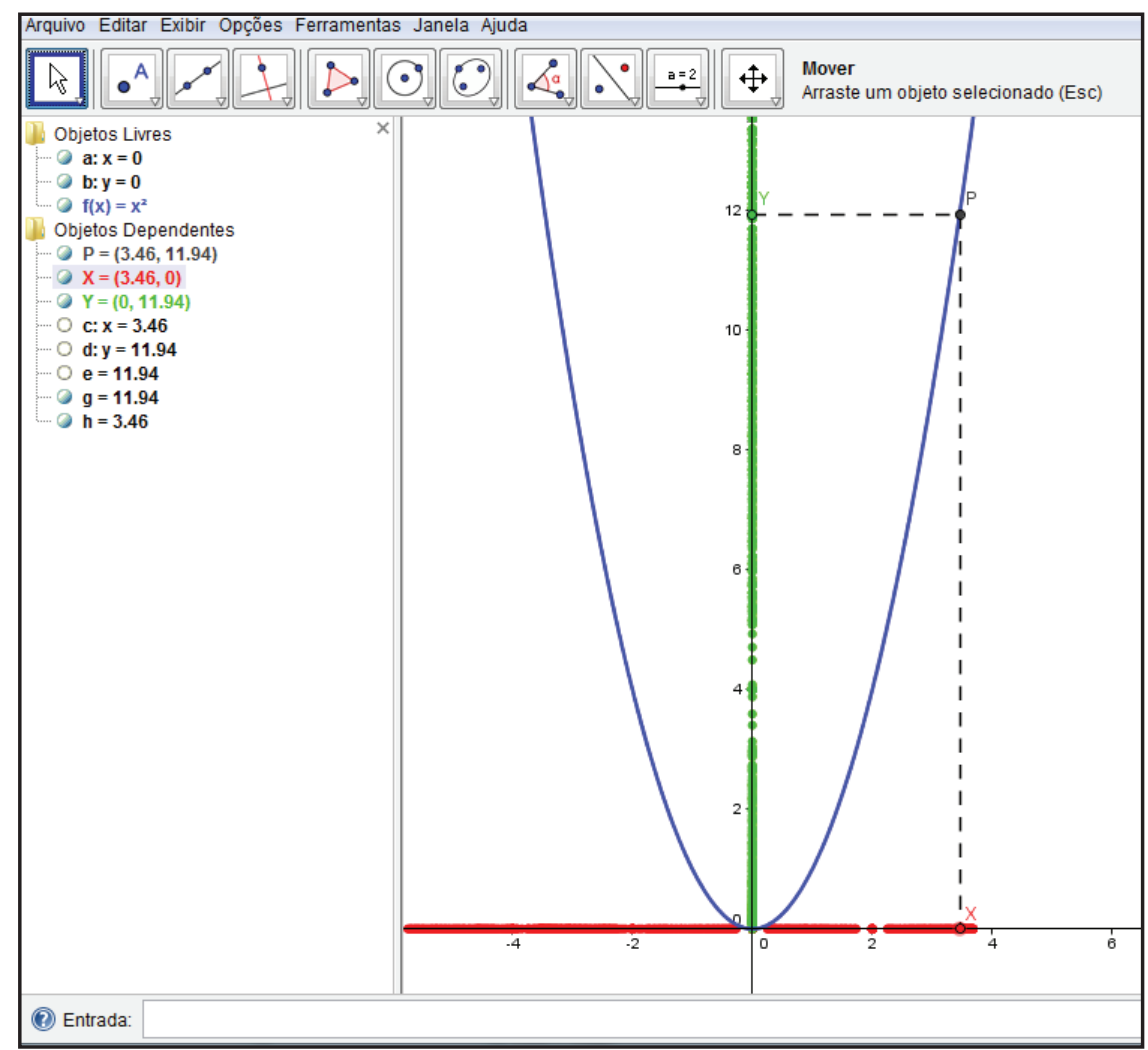

Figura 2 - Construção feita por Az para a Atividade que explorava o domínio e a imagem da função $f(x)=x^{2}$, a partir da movimentação do ponto $\mathrm{X}$ sobre o eixo OX.

Depois da construção, os alunos receberam questões para responder explorando o objeto construído. Nesses questionamentos os alunos mostraram identificar o "rastro" em vermelho, ao longo de todo o eixo OX como "os possíveis valores que $x$ pode assumir" conforme comentários em linhas gerais dos alunos $A_{12}, A_{11}, A_{7}, A_{2}$, sendo que nenhum aluno citou, especificamente, como domínio da função, mas sim seu significado geométrico. O "rastro" em verde, a imagem da função de acordo com os valores assumidos para $x$, foi identificado, pelos estudantes, através de seu significado algébrico: "no eixo OY ficam marcados, no rastro em verde, os quadrados dos números marcados no eixo OX" (A4).
Os estudantes observaram nessa construção, que alguns pontos do eixo OX e OY não ficaram marcados, porém ao serem orientados a utilizar a função "zoom" puderam perceber que, na medida o "zoom" aumentava o software fornecia um "rastro" cada vez mais contínuo.

Essa atividade foi o ponto de partida para trabalhar o conceito de limite de uma função nas proximidades de um ponto de seu domínio. Em seguida, os estudantes preencheram corretamente, as tabelas propostas, conforme exemplo abaixo, (figuras 3 e 4), com o objetivo de concluir sobre o limite da função $f(x)=x^{2}$ para valores de $x$ se aproximando cada vez mais de 3 , pela esquerda e pela direita. 


\begin{tabular}{|c|c|c|c|c|c|c|c|}
\hline PONTO & A & B & C & D & E & F & G \\
\hline$x$ & 2 & 2.5 & 2.8 & 2.9 & 2.99 & 2.999 & 2.9999 \\
\hline$f(x)$ & 4 & 6,25 & 7.84 & 8,41 & 8,9401 & 8994001 & 19994007 \\
\hline
\end{tabular}

Figura 3 - Tabela de A5 para concluir sobre o limite de $f(x)$ para $x$ tendendo a 3, pela esquerda.

\begin{tabular}{|c|c|c|c|c|c|c|c|}
\hline PONTO & H & I & J & K & L & M & N \\
\hline$x$ & 4 & 3.5 & 3.2 & 3.1 & 3.01 & 3.001 & 3.0001 \\
\hline$f(x)$ & 16 & 12,25 & 1024 & 9,61 & 9,0601 & 9,006001 & 9,00000001 \\
\hline
\end{tabular}

Figura 4: Tabela de $\mathrm{A}_{5}$ para concluir sobre o limite de $f(x)$ para $x$ tendendo a 3, pela direita.

Essa atividade, além de servir para introduzir a ideia intuitiva de limite de uma função, também possibilitou aos estudantes conhecer a simbologia para representar esse fato. Assim, concluíram nesta etapa a partir das orientações que: $\lim _{x \rightarrow 3} x^{2}=9$.

Na complementação da atividade, os alunos precisavam fazer um esboço do gráfico de uma das funções que estavam considerando, com base na visualização no software, e indicar o significado geométrico do limite calculado. A ideia de aproximação estava presente em todos os esboços feitos, por exemplo, o apresentado na figura 5.

As ilustrações deixam em evidência o entendimento dos alunos sobre o significado de limite, ou seja, o processo infinito de aproximação: na medida em que os valores de $x$ se aproximam cada vez mais de 2 , tanto pela direita quanto pela esquerda, os valores de $f(x)$ se aproximam cada vez mais de 3 .

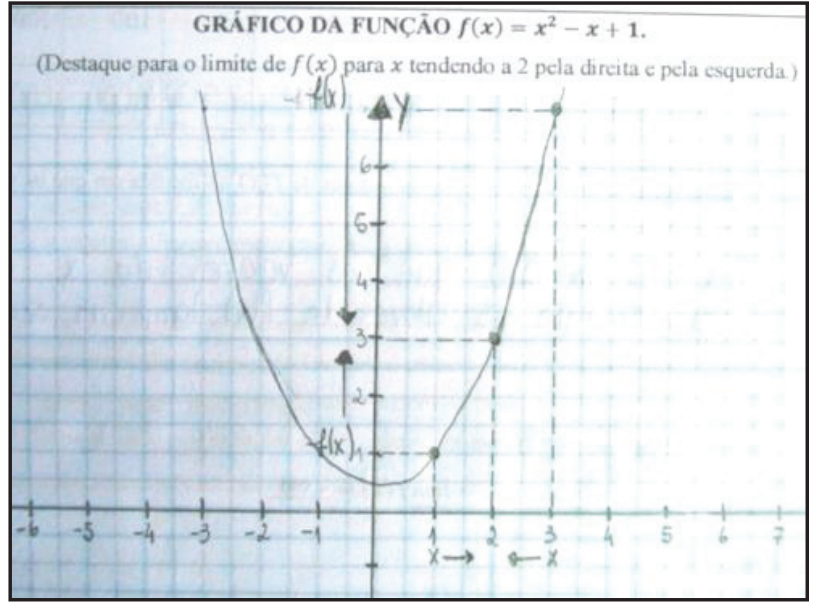

Figura 5 - Gráfico feito por $\mathrm{A}_{2}$ para a atividade da interpretação geométrica sobre o significado de limite de uma função em um ponto do seu domínio.

Nas atividades seguintes os estudantes foram direcionados ao estudo do comportamento dos valores de $f(x)=x^{2}$, para valores de $x$ cada vez maiores (ou cada vez menores), introduzindo assim o conceito de limites infinitos. Todos os alunos apresentaram os cálculos e concluíram corretamente esta atividade, compreendendo o significado das expressões:

$$
\begin{array}{ccc}
\lim _{x \rightarrow-\infty} x^{2}=+\infty & \text { e } \lim _{x \rightarrow+\infty} x^{2}=+\infty . \\
\text { Para } & \text { exemplificar, estão } \\
\text { apresentadas } & \text { abaixo algumas das }
\end{array}
$$


justificativas dos estudantes para as duas questões apresentadas:

a) $\mathrm{O}$ que acontece com os valores de $f(x)$ na medida em que os valores de $x$ crescem cada vez mais?

"São infinitos, vão crescendo cada vez mais". $\left(\mathrm{A}_{10}\right)$

"O valor de $f(x)$ cresce cada vez mais na medida em que o $x$ cresce". (A $\left.\mathrm{A}_{7}\right)$

"Também vão crescendo cada vez mais". (A4)

b) $O$ que acontece com os valores de $f(x)$ na medida em que os valores de $x$ decrescem cada vez mais?

"Vão aumentando cada vez mais".(A9)

"Na medida em que os valores de $x$ decrescem cada vez mais os valores de $f(x)$ continuam aumentando". (A7)

"Cada vez que $x$ decresce, $f(x)$ cresce cada vez mais". ( $\left.\mathrm{A}_{12}\right)$

De forma análoga, os estudantes analisaram o comportamento para os valores de $f(x)=-x^{2}$, com valores de $x$ cada vez maiores (ou cada vez menores), e também os alunos apresentaram os cálculos e conclusões corretas.

Os estudantes também exploraram outros três exemplos de funções, analisando o limite para $x$ tendendo a um valor do domínio da função e para valores cada vez maiores ou menores, ou seja, seus limites no infinito. As anotações dos estudantes consideram a noção de aproximação infinita e valores infinitos (cada vez maiores ou menores).

Destaca-se que, apesar da aplicação de limites às funções quadráticas ser bastante simples e diretamente visível através do seu gráfico, ou até pela própria correspondência $(x, f(x))$ é importante introduzir essa análise logo no primeiro ano do Ensino Médio, de modo a levar os estudantes a refletirem acerca do comportamento gráfico de uma função. Assim, esse gráfico pode ser esboçado com melhor convicção pelos estudantes ao relacionarem esses conceitos.

Acredita-se também que, ao trabalhar com outras funções, é possível inclusive analisar o comportamento assintótico de alguns gráficos como o de funções exponenciais e logarítmicas. Merece também destaque o fato do grande ganho em linguagem, simbolismo e conhecimento matemático que o estudante pode adquirir ao trabalhar dessa maneira mais direcionada. Considerando que limites é, na maioria das vezes, o primeiro assunto do curso de cálculo e já é, de fato, apresentado ao estudante nas primeiras aulas dessa disciplina, o trabalho intuitivo, aplicado a funções simples no Ensino Médio, pode representar um ganho razoável em aprendizado logo no início da vida universitária desses estudantes.

\subsection{Roteiro de atividades 3}

Nesta terceira etapa da realização das atividades com os estudantes, pretendia-se, de modo intuitivo, introduzir o significado da derivada de uma função, de acordo com o que é sugerido por Ávila (2006). As atividades que foram aplicadas exploravam a aproximação do cálculo da velocidade instantânea de um objeto, dada a equação de seu movimento (ou informações sobre a posição do objeto em cada instante de tempo a ser 
analisado), e sugerem a compreensão do significado das expressões "taxa de variação média" e "taxa de variação instantânea".

Além disso, na sequência, esse roteiro buscou abordar o conceito de derivada a partir da construção da reta tangente a um ponto $P=(x, f(x))$ do gráfico de uma função a partir de uma reta secante que passa pelo ponto $P$ e por um ponto $Q=(x+h, f(x+h))$. O conceito de derivada, neste caso, foi explorado através de um processo de aproximação o qual consistia em fazer essa reta secante tender à posição tangente analisando o seu coeficiente angular, ou seja, a razão $\frac{\Delta y}{\Delta x^{\prime}}$ em cada instante, na medida em que $h$ se aproximava cada vez mais de zero. No GeoGebra a interpretação feita pelos estudantes foi semelhante, eles analisaram essa razão na medida em que o ponto $Q$ se aproximava cada vez mais do ponto $P$.

Assim, o que interessava naquele momento, era exatamente o que Ávila descreveu, ao analisar a figura 6 sem, no entanto, a necessidade de utilizar a denominação "derivada".

A reta secante vai passando por várias posições, aproximando-se de uma posição limite, uma reta limite, por assim dizer, a qual é definida como sendo a reta tangente à curva no ponto P. [...] Repare que $h$ nunca é zero, pois esse valor não faria sentido na razão incremental $\Delta y / h$. O que nos interessa é saber o valor limite dessa razão, o valor do qual ela pode se tornar tão próxima quanto quisermos, bastando para isso fazer $h$ suficientemente pequeno. Esse limite é o que se chama a derivada da função no valor $x$ da variável independente. (ÁVILA, 2006, p.34, grifo do autor).

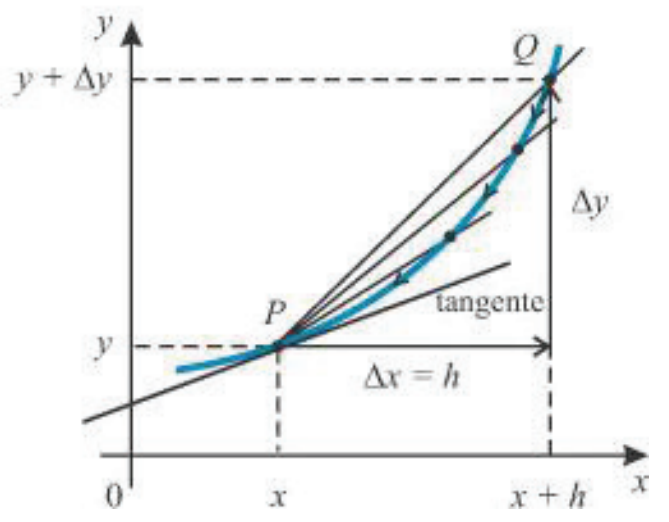

Figura 6 - Reta secante tendendo à reta tangente no ponto P. Fonte: (ÁVILA, 2006, P.34).

Para dar início a estes tópicos, apresentou-se uma situação-problema envolvendo o deslocamento de um automóvel em função do tempo. A ideia era trabalhar inicialmente com o conceito de velocidade média. Nessa etapa para calcular a velocidade média $\left(V_{M e ́ d}\right)$, bastava considerar a razão (taxa) entre a distância percorrida por um objeto $(\Delta d)$ e o tempo gasto nesse deslocamento $(\Delta t)$, ou seja, $V_{M e ́ d}=\frac{\Delta d}{\Delta t}$, conforme já tinham estudado na disciplina de Física.

Com base nisso, o objetivo dessa atividade, era relacionar a velocidade média com o cálculo do coeficiente angular de uma reta cujo significado até então era: a razão entre a variação dos valores da variável dependente y em relação à variação sofrida pela variável independente $x$ da função $f(x)$ num certo intervalo.

Analisando as respostas dos estudantes, verificou-se que todos efetuaram corretamente o cálculo da velocidade média pedida em cada um dos exemplos apresentados. Por exemplo, no item que questionava: "Qual é o coeficiente angular da reta que representa o movimento desse objeto? Você 
consegue perceber alguma relação entre o coeficiente angular e a velocidade média, calculada nesse caso?", mereceu destaque o fato de que, a maioria dos alunos estabeleceu as relações esperadas entre o coeficiente angular da reta que é gráfico da função $f(x)=3 x-2$ (explorada nesta atividade!) e a velocidade média, para essa equação do movimento de um objeto, no intervalo de 1 a 3 segundos.

"A velocidade média e o coeficiente angular são calculados de forma igual". ( $\left.\mathrm{A}_{2}\right)$

"O coeficiente angular é 3, o coeficiente angular é calculado desta forma $m=\frac{\Delta y}{\Delta x}$ e a velocidade média é $V_{m}=\frac{\Delta y}{\Delta x^{\prime}}$ eles são calculados iguais". (As)

"O coeficiente é 3 [...] é feita a variação do y dividida pela variação do $x$ nos dois casos, na velocidade média e no coeficiente angular".(A4 e $\left.\mathrm{A}_{5}\right)$

"O coeficiente angular da reta que passa pelos pontos solicitados é igual a velocidade média" $\left(\mathrm{A}_{10}\right)$

O desafio proposto aos estudantes, na sequência das atividades, referia-se a compreensão do conceito e do cálculo da aproximação da velocidade instantânea de um objeto, ou seja, determinar sua velocidade em um determinado instante.

Para isso, foi utilizado um exemplo apresentado no material da disciplina Fundamentos de Cálculo do Profmat, conforme segue.

Exemplo: Imagine a situação em que um jogador de vôlei foi sacar, levantou a bola, mas se arrependeu e a bola caiu muito próxima do ponto onde foi lançada. Imagine que esse movimento todo tenha levado um pouco mais de 2 segundos e que a partir de fotografias tiradas em intervalos regulares foi possível dizer a altura da bola a cada segundo, apresentados na tabela a seguir. Qual é a velocidade da bola no instante $x=$ 1 ?

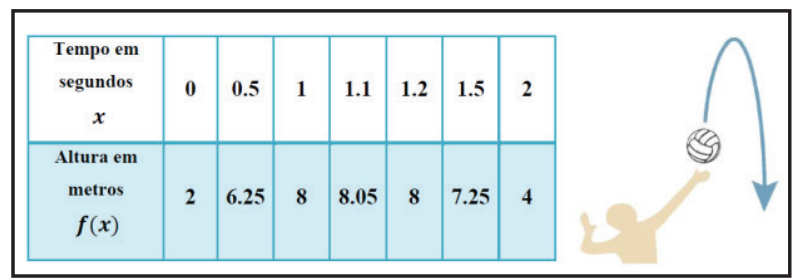

Figura 7 - Ilustração e tabela de valores. Fonte: SBM - Fundamentos de Cálculo

Com base na figura 7, para responder a essa pergunta os alunos primeiramente preencheram uma tabela, calculando a velocidade média $\left(V_{\text {Méd }}=\frac{\Delta y}{\Delta x}\right)$, em vários intervalos, cada vez menores, e com extremo superior cada vez mais próximo de 1 , a fim de aproximar a velocidade média da velocidade instantânea da bola no tempo $x=1$. Os estudantes perceberam que os intervalos considerados tinham amplitude cada vez menor, sendo que no último intervalo, entre 1 e 1,1 segundos já obtiveram uma boa aproximação para a velocidade procurada, obtendo $0,5 \mathrm{~m} / \mathrm{s}$.

Com essa atividade os alunos perceberam que quanto menor $\mathrm{O}$ intervalo de tempo que for sendo considerado mais próximo o cálculo da velocidade média estará da velocidade no instante procurado. Com esse exemplo, foi possível introduzir, além do conceito de velocidade instantânea e a aproximação do seu cálculo, também a notação adequada, que nos fornece exatamente a ideia intuitiva do procedimento de aproximação que foi realizado:

$$
\lim _{\Delta x \rightarrow 0} V_{\text {méd }}=\lim _{\Delta x \rightarrow 0} \frac{\Delta y}{\Delta x}
$$


Essa notação, ao ser trabalhada com os estudantes, possibilitou $\mathrm{O}$ entendimento de que quanto menor o intervalo de tempo considerado, ou seja, quanto mais próximo de zero tomarmos $\Delta x$, mais próxima a velocidade média fica da velocidade instantânea.

As atividades seguintes visavam abordar a construção e o entendimento do significado de reta tangente ao gráfico de uma função. Além disso, as mesmas pretendiam, através da análise do coeficiente angular dessa reta em pontos do domínio da função, concluir acerca do comportamento do seu gráfico, relacionando esse conceito aos conhecimentos prévios dos estudantes sobre intervalos de crescimento, decrescimento e concavidade de uma função quadrática.

Para iniciar o estudo desses tópicos, os estudantes foram orientados a construir, no GeoGebra o gráfico da função $f(x)=x^{2}$. Em seguida, inseriram o ponto $P=(1, f(1))$ sobre o gráfico da função. Com auxílio do recurso "Seletor" desse software, inseriram um parâmetro " $a$ " variando de 1.1 (mínimo) a 3 (máximo), acrescentaram o ponto $Q=(a, f(a))$ e a reta que passava por $P$ e $Q$. Essa construção possibilitava aos estudantes movimentar o parâmetro inserido e analisar a posição da reta $P Q$ construída. $\mathrm{Na}$ verdade, essa reta, secante por $P$ e $Q$ ao gráfico de $f(x)=$ $x^{2}$ se aproximava cada vez mais da reta tangente em $x=1$, na medida em que o parâmetro " $a$ " se aproximava cada vez mais de 1.

A figura 8 apresenta algumas das retas secantes obtidas nessa atividade. $\mathrm{A}$ construção feita por $\mathrm{A}_{2}$, com $\mathrm{o}$ recurso "Habilitar rastro" deixa em evidência a sequência de retas formadas de acordo com a movimentação do parâmetro " $a$ " inserido. As questões propostas na sequência exigiam dos estudantes o cálculo do coeficiente angular das retas secantes obtidas e a anotação de suas conclusões em uma tabela.

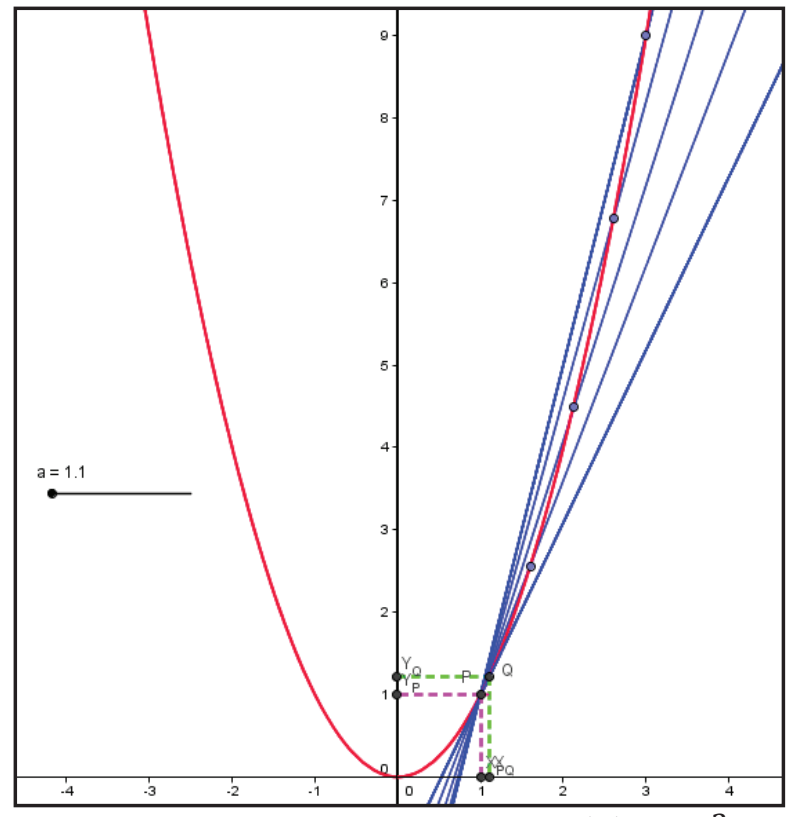

Figura 8 - Reta secante a $f(x)=x^{2}$ tendendo a posição tangente em $x=1$.

A reta tangente ao gráfico de $f(x)=x^{2}$ foi definida como sendo a reta limite dessa aproximação, ou seja, a reta de equação $y=a x+b$, que só possui em comum com o gráfico da função o ponto $P$, neste caso $P=(1, f(1))$. O desafio proposto aos estudantes, após essa definição era a obtenção da equação da reta tangente ao gráfico dessa função. Para isso, era necessário encontrar (ou melhor, aproximar) o coeficiente angular da reta tangente no ponto desejado. Mas essa tarefa, a essa altura, pareceu simples aos estudantes, uma vez que já tinham obtido aproximações para esse coeficiente angular.

Entre os 14 estudantes que fizeram essa atividade, todos 
concluíram, através da observação e dos cálculos dos coeficientes angulares que haviam realizado, que na medida em que o valor do parâmetro " $a$ " se aproximava cada vez mais de 1 , o ponto $Q$ se aproximava cada vez mais do ponto $P$, e a reta $P Q$ se aproximava da posição da reta tangente em $x=1$.

Dando continuidade ao trabalho, os alunos utilizaram um recurso do GeoGebra denominado "Tangentes" e traçaram a equação da reta tangente ao gráfico de $f(x)=-x^{2}+3$ no ponto $P=(1, f(1))$, ou seja, em $P=(1,2)$. Depois, sem aviso prévio de que a equação da reta já estava visível na janela algébrica do software, os estudantes determinaram dois pontos dessa reta, calcularam seu coeficiente angular e montaram a equação da reta tangente.

O estudo do comportamento de uma função quadrática, bem como a identificação dos intervalos de crescimento ou decrescimento da função, a noção de pontos de máximo ou de mínimo de uma função foram explorados, em uma outra atividade, a partir da análise da inclinação da reta tangente a curva de cada gráfico. Inicialmente os estudantes construíram no software o gráfico de $f(x)=x^{2}$ inseriram um parâmetro " $a$ " $\mathrm{e}$ marcaram, sobre o gráfico o ponto $P=(a, f(a))$. A seguir, construíram a reta tangente a $f(x)$ em $P$, depois foram orientados a utilizar $O$ recurso "inclinação", o qual fornece diretamente na janela algébrica o valor do coeficiente angular da reta.

Com essa ferramenta do GeoGebra os estudantes conseguiam visualizar as respectivas variações $\Delta x \mathrm{e}$
$\Delta y$ em um intervalo considerado pelo software, bem como o valor do coeficiente angular da reta tangente que foi traçada. Os estudantes perceberam que, na verdade, essa nova ferramenta, fornecia a eles as informações que eles haviam precisado calcular na atividade anterior.

Após a observação da construção realizada, os alunos preencheram uma tabela com informações sobre a reta tangente ao gráfico da função de acordo com modificações no parâmetro " $a$ " que havia sido inserido. A partir da visualização, os estudantes não demonstraram dificuldades em identificar os intervalos de crescimento e decrescimento da função quadrática em questão e relacioná-los com os intervalos onde o coeficiente angular da reta tangente ao gráfico era respectivamente, positivo ou negativo.

Além disso, os estudantes foram indagados a identificar alguma relação existente entre o parâmetro " $a$ ", que representava a abscissa $x$ de cada ponto $P$ e o valor respectivo do coeficiente angular em cada ponto. O objetivo desse questionamento é a percepção intuitiva de que, para a função $f(x)=x^{2}$, temos $f^{\prime}(x)=2 x$, sendo $f^{\prime}(x)$ a derivada da função $f(x)$. A partir das observações dos estudantes que serão apresentadas, percebe-se que os estudantes conseguiram fazer relações corretas e apresentaram respostas coerentes ao questionamento:

"A abscissa ' $a$ ' é multiplicada por 2". $\left(\mathrm{A}_{10}\right)$

"O coeficiente angular da reta é sempre o dobro do parâmetro 'a', e também é o dobro dos valores da abscissa $x^{\prime \prime}$. (A 5 ) 
"O coeficiente angular da reta é sempre o dobro do valor de $x$ em cada ponto". (A $\mathrm{A}_{11}, \mathrm{~A}_{6}$, $\mathrm{A}_{8}$ e $\mathrm{A}_{12}$ )

"O valor de ' $m$ ' é o dobro do valor da abscissa ' $x$ ' de cada ponto". $\left(\mathrm{A}_{2}\right)$

$\mathrm{Na}$ sequência, foi sugerida aos estudantes uma análise semelhante para a função $f(x)=-x^{2}$ e para outras duas funções: $\quad f(x)=x^{2}-4 x+2 \quad \mathrm{e}$ $f(x)=-x^{2}+6 x-4$. Foram observadas as características de cada função de modo a tirar conclusões importantes acerca do comportamento e o traçado do gráfico de uma função quadrática, como identificar as coordenadas do ponto de máximo ou de mínimo de cada função, seu intervalo de crescimento e decrescimento em relação ao intervalo que fornecia, respectivamente, coeficiente angular da reta tangente, positivo ou negativo, nos pontos pertencentes a cada intervalo considerado.

Dessa forma, os estudantes puderam perceber que:

$>$ Quando o coeficiente angular da reta tangente for positivo em um intervalo de variação do domínio da função, a função será CRESCENTE nesse intervalo.

$>$ Quando o coeficiente angular da reta tangente for negativo em um intervalo de variação do domínio da função, a função será DECRESCENTE nesse intervalo.

$>$ Quando o coeficiente angular da reta tangente for nulo em um ponto $P$ (no caso da função quadrática), esse ponto é o ponto de máximo ou ponto de mínimo da função dada.

$>P=(x, y)$ será ponto de máximo da função $f(x)$, se o coeficiente angular da reta tangente ao gráfico passar de positivo para negativo, ou seja, se a função $f(x)$ é crescente para valores do dominio menores que $x$ e decrescente para valores maiores de $x$.

$>$ Caso contrário, $P=(x, y)$ será ponto de mínimo, ou seja, a função é decrescente até o ponto $P$ e cresce a partir dele.

Merece destaque o fato de que todas as observações acima podem ser obtidas a partir da derivada primeira (e/ou segunda) de uma função, que geralmente estão relacionados com os estudos relativos às disciplinas iniciais de Cálculo do Ensino Superior. No entanto, pode-se verificar que é possível introduzir, o conceito de derivada, de forma intuitiva e baseada na visualização e experimentação para alunos ainda no primeiro ano do Ensino Médio. Além disso, sem aprofundar em detalhes, os alunos podem ser induzidos a tirar as mesmas conclusões permitidas pelo uso das derivadas no Ensino Superior e obter informações relevantes sobre o comportamento de uma função.

Segundo Ávila (2006, p.32) é possível ainda, justificar aos estudantes sobre a concavidade (para cima ou para baixo) de uma função quadrática a partir da inclinação da reta tangente, pois “dizer que a concavidade da curva está voltada para cima significa precisamente que o declive da reta tangente cresce à medida que crescem os valores atribuídos a $x^{\prime \prime}$.

\subsection{Roteiro de atividades 4}

Nesta etapa do trabalho, as atividades propostas tinham como objetivo principal determinar a área limitada pelo gráfico de uma função 
$f(x)$, cujo conjunto imagem é não negativo, pelo eixo das abscissas e num intervalo $[a, b]$ do seu domínio, ou seja, a região limitada pelas retas $x=a$ e $x=b$, conforme a figura 9.

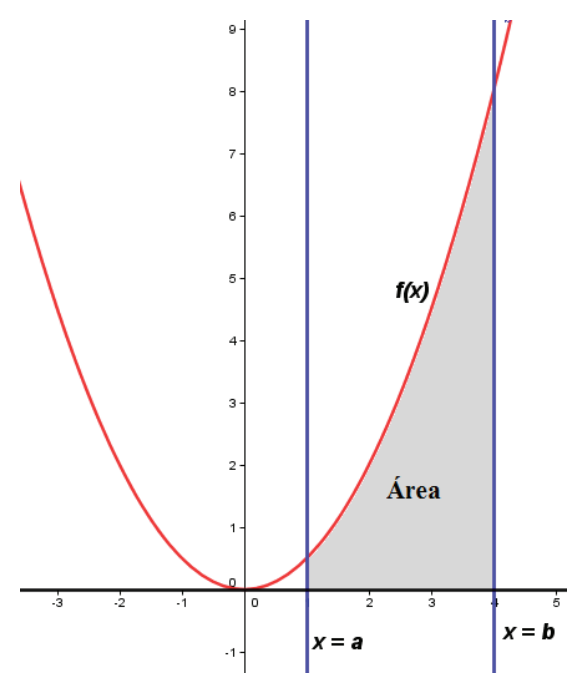

Figura 9 - Área limitada pelo gráfico da função $f(x)=x^{2}$ e pelo eixo das abscissas num intervalo $[a, b]$ do seu domínio.

A intenção das atividades era apresentar, de forma intuitiva, através de aproximações sucessivas utilizando retângulos por baixo e por cima da curva da função no intervalo considerado, uma forma de calcular a área dessa região. Note que essa ideia é exatamente o conceito de integral definida de uma função $f(x)$ em um intervalo $[a, b]$ do seu domínio que, no Ensino Superior, representamos por $\int_{a}^{b} f(x) d x$.

Para as atividades propostas, o software GeoGebra teve uma importância bastante significativa, já que foram explorados os recursos "Soma Superior" e "Soma Inferior". Esses recursos possibilitam a visualização dos retângulos utilizados para a aproximação da área, de modo que, ao aumentar a quantidade de retângulos, mais próxima a soma das suas áreas fica da área da região que se deseja calcular.
Assim, além de possibilitar a visualização, a utilização do GeoGebra foi imprescindível para a compreensão da ideia intuitiva de integral definida.

Foi possível verificar que os estudantes, a partir de seus conhecimentos prévios sobre o cálculo de áreas, sobre funções e utilizando o software matemático e a ideia de aproximações sucessivas, conseguiram calcular corretamente as áreas descritas nas atividades.

Sabe-se que, desde o Ensino Fundamental, o aluno aprende a calcular a área de regiões planas como retângulos, quadrados, triângulos, trapézios, etc. Assim, nas atividades iniciais desta etapa, os estudantes relembraram o cálculo da área dessas figuras, especialmente de retângulos e triângulos. Foi proposta uma ampliação da aplicação das fórmulas conhecidas para o cálculo de áreas de triângulos e retângulos, a fim de calcular a área da região limitada por uma função de $1^{\circ}$ grau e o eixo OX em um intervalo $[a, b]$ do domínio dessa função. Para isso, bastava que os estudantes observassem que como o gráfico de uma função do $1^{\circ}$ grau é uma reta, podiam identificar a região do gráfico limitada pela reta e pelo eixo OX, como um triângulo (Caso 1: Figura 10) ou como a união de um retângulo $\mathrm{A}_{1}$ com um triângulo $\mathrm{A}_{2}$ (Caso 2: Figura 10) e, neste caso, a área da região é a soma das áreas: $\mathrm{A}=\mathrm{A}_{1}+\mathrm{A}_{2}$. Nesse segundo caso, poderia ser trabalhado ainda com o cálculo da área de um trapézio de bases medindo $f(b)$ e $f(a)$ e altura $(b-a)$. 


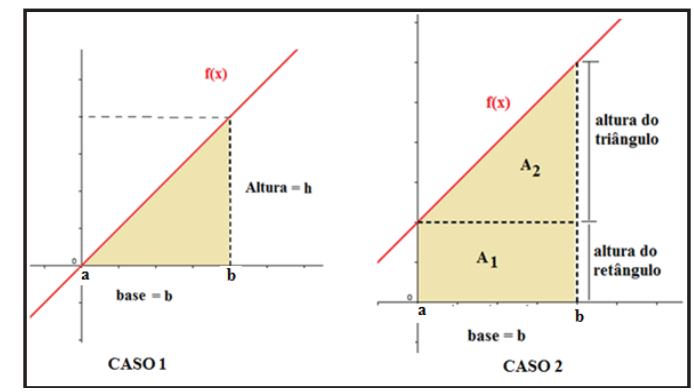

Figura 10 - Região limitada por uma função de $1^{\circ}$ grau e o eixo OX em um intervalo $[a, b]$.

No GeoGebra, os alunos foram orientados a construir o gráfico de cada função e inserir as retas verticais $x=a \mathrm{e}$ $x=b$, de acordo com o intervalo $[a, b]$ considerado em cada caso. Depois disso, precisavam identificar a base e a altura correspondentes em cada caso para em seguida determinar a área da região especificada, sempre limitada pelo eixo OX.

O próximo desafio proposto aos estudantes foi: como calcular a área de uma região que não pode ser diretamente comparada a uma figura plana conhecida? Para tentar responder a essa pergunta, a seguinte situação foi apresentada: Estamos interessados agora em determinar a área limitada pelo eixo OX, pelo gráfico de uma função contínua e positiva, por exemplo, $f(x)=x^{2}$, e uma reta vertical, por exemplo, $x=2$, como apresentado na figura 11. Pense em uma maneira de fornecer um valor aproximado para a área pintada. Que valor você obteve?

Vários alunos apresentaram respostas bastante curiosas a essa atividade, utilizando a aproximação por triângulos e por retângulos, estimando alguns pontos sobre o gráfico para efetuarem seus cálculos.

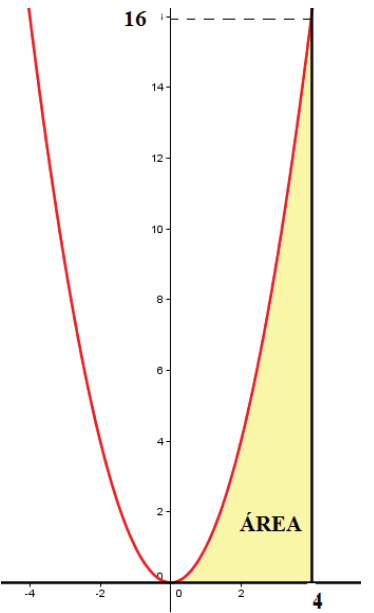

Figura 11- Região limitada por $f(x)=x^{2}$ e o eixo OX no intervalo $[0,4]$ para aproximação da área.

$\mathrm{Na}$ sequência o objetivo era aproximar a área sob a curva da função $f(x)=x^{2}$, limitada pelo eixo OX no intervalo $\quad[0,4]$ Primeiramente, utilizando o comando "Soma Superior" do software GeoGebra, e a soma das áreas de quatro retângulos, de base 1 e com altura determinada pela ordenada do ponto de intersecção do retângulo criado com o gráfico da função. Neste caso, a área foi aproximada, por excesso. Posteriormente, os alunos foram orientados a utilizar o comando "Soma Inferior" para aproximar por falta a área descrita, também utilizando quatro retângulos, de modo análogo ao item anterior.

Observe na figura 12, a construção feita por um dos alunos para a atividade. Note que os retângulos em azul estão sobrepostos aos retângulos em vermelho. 


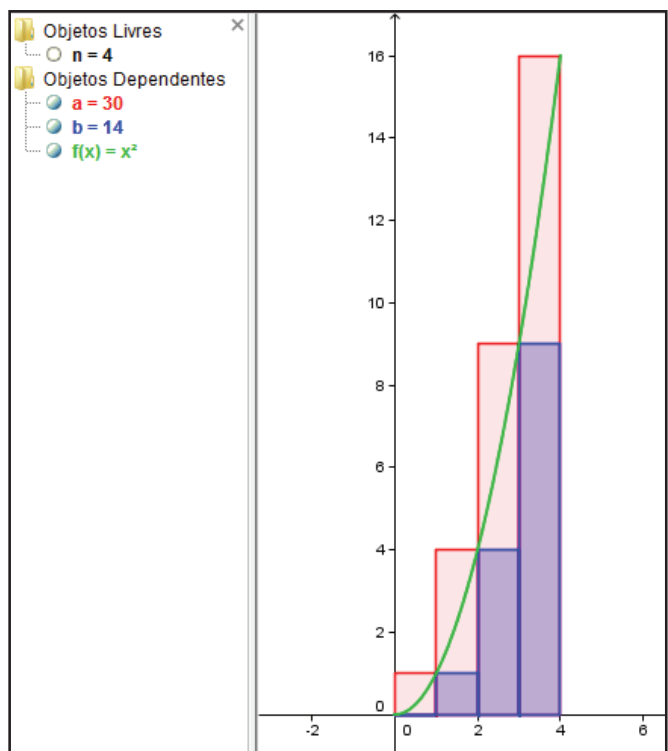

Figura 12 - Aproximação da área descrita na atividade 18 feita por A7 no

GeoGebra

Pode-se observar também que o parâmetro " $a$ " que aparece (em vermelho) na janela algébrica do GeoGebra (Figura 12) indica a aproximação da área por excesso, ou seja, somando a área dos quatro retângulos vermelhos. Da mesma forma, o parâmetro " $b$ " indica a aproximação da área por falta, ou seja, pela soma das áreas dos retângulos em azul. Assim, tem-se que a área procurada está limitada por esses parâmetros, ou seja, $a>$ Área procurada $>b$.
Podemos dizer ainda que, a área da região abaixo da curva do gráfico que queremos calcular fica limitada pelos valores da Soma Superior e Soma Inferior.

Com base nisso, os alunos foram orientados a aumentar o número de retângulos, utilizando o recurso "Seletor" do GeoGebra, e encontrar valores cada vez mais próximos da área real abaixo do gráfico da função $f(x)=x^{2}$, limitada pelo eixo OX, no intervalo $[0,4]$. Na medida em que faziam esse procedimento, anotavam em seus materiais os valores aproximados obtidos, de modo que para 1000 retângulos os valores obtidos para o parâmetro Soma Superior " $a$ " foi 21,37 unidades de área e para o parâmetro Soma Inferior " $b$ " a aproximação obtida foi 21,3 unidades de área.

Todos os alunos conseguiram utilizar os recursos do software GeoGebra necessários a essa atividade e conseguiram perceber, que na medida em que o número de retângulos aumentava cada vez mais, as aproximações obtidas eram cada vez melhores, conforme é possível notar na figura 13.

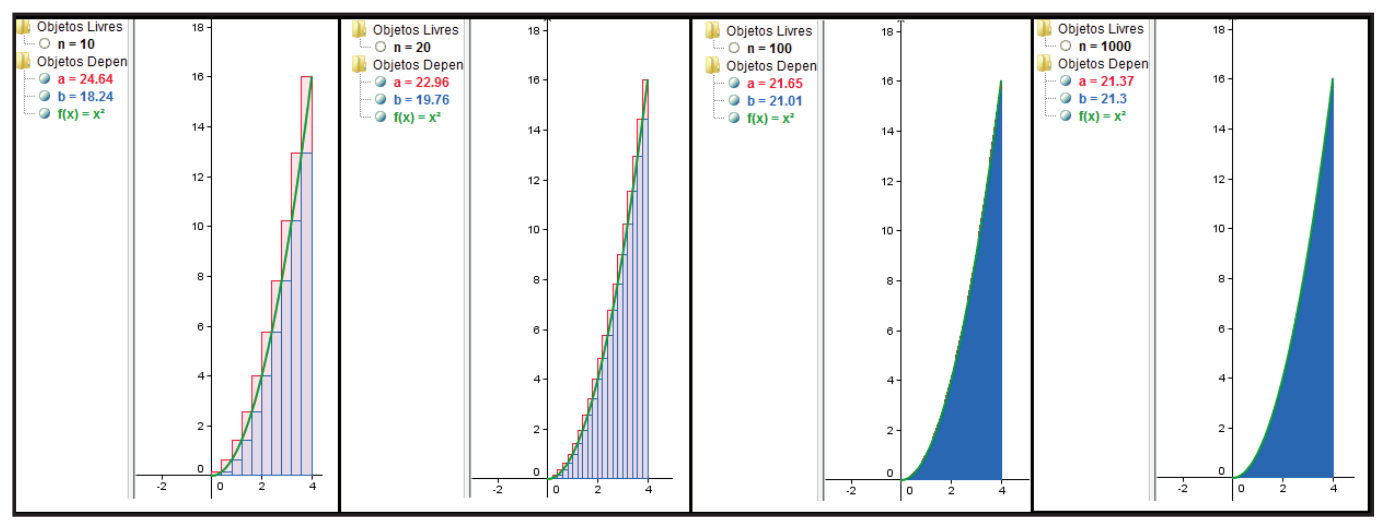

Figura 13 - Aumentando o número de retângulos 


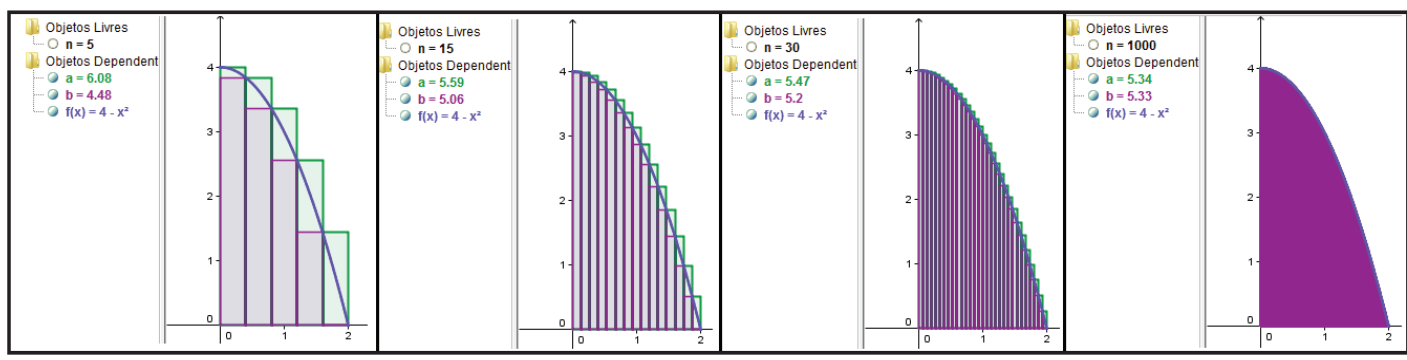

Figura 14 - Aproximações sucessivas para a área descrita na atividade 19, realizadas por A5.

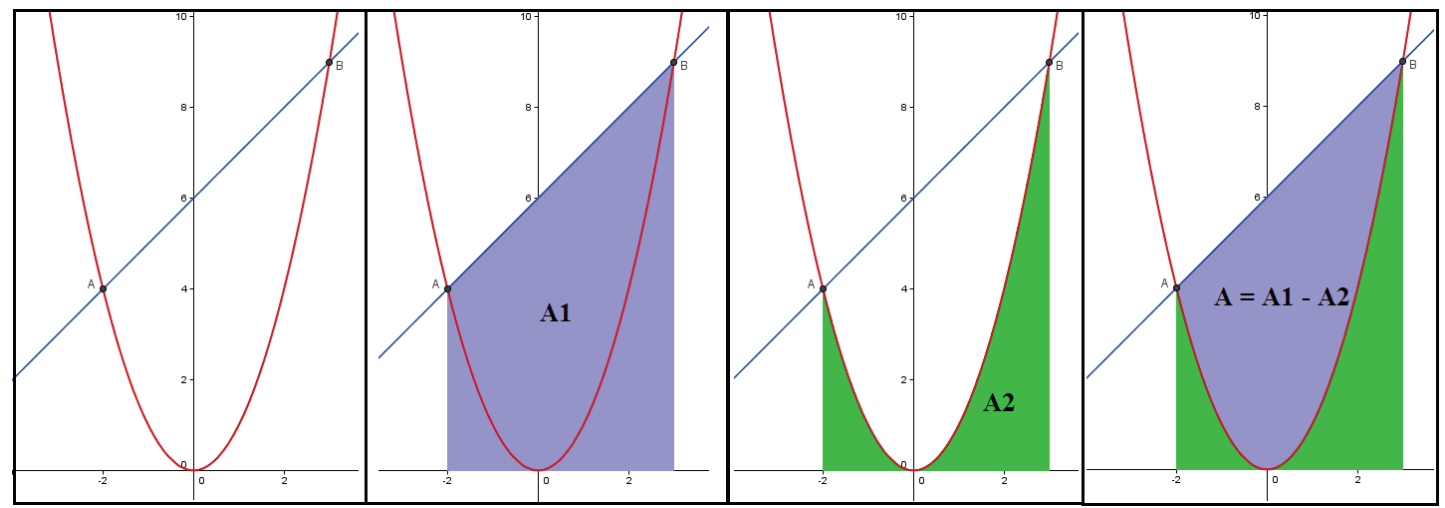

Figura 15 - Área de uma região limitada por duas funções

Em seguida utilizou-se o mesmo procedimento para a função quadrática $f(x)=4-x^{2}$ no intervalo $[0,2]$, a fim de aproximar a área sob o gráfico da função, limitada pelo eixo $O X$ no intervalo considerado. Sem dificuldade, todos os alunos conseguiram encontrar uma boa aproximação para a área, obtendo 5,3 unidades de área. Já que na medida em que o número de retângulos aumentava cada vez mais, o valor da área da região se aproximava cada vez mais de 5,3, como é possível analisar na figura 14

As atividades propostas na sequência desse quarto roteiro visaram apresentar aos estudantes como calcular a área da região limitada por duas funções em um intervalo $[a, b]$, onde $a$ e $b$ são as abscissas dos pontos de intersecção dos respectivos gráficos. Um dos exemplos trabalhados nessa etapa tinha como objetivo orientar os estudantes para o cálculo da área da região limitada entre as curvas de $g(x)=x^{2}$ e $f(x)=x+6$ (Figura 15)..
Após a identificação da região, a qual se desejava calcular a área, conforme pode ser visualizado na figura 15, o procedimento adotado para a aproximação do valor da área dessa região é o mesmo das atividades anteriores, trabalhando separadamente com cada função no intervalo identificado.

Com base nisso, para as funções dessa atividade, os alunos identificaram o intervalo $[-2,3]$ já que para $x=-2$ e $x=3$ tem-se que $f(x)=g(x)$. Assim, as aproximações obtidas pelos alunos foram:

Área da região $\mathrm{A} \mathbf{1}=\mathbf{3 2 , 4 9}$

Área da região $\mathrm{A} 2=\mathbf{1 1}, \mathbf{6 3}$

Área desejada: $\mathrm{A}=\mathbf{A} \mathbf{1}-\mathbf{A} \mathbf{2}=\mathbf{2 0 , 8 6}$

Apesar da análise sucinta que foi apresentada nesta última etapa, merece 
destaque, que todas as atividades buscavam explorar a ideia de aproximação das áreas das regiões definidas em cada exercício. A ideia intuitiva de "integral definida" foi trabalhada a partir da observação e da experimentação proporcionada pelo software GeoGebra, de modo que os alunos pudessem perceber que, quanto maior o número de retângulos considerados, melhor seria a aproximação para o valor da área desejada.

A avaliação desse roteiro por parte dos estudantes evidencia que os objetivos traçados para o mesmo foram alcançados. Os estudantes foram capazes de estender o conceito de área de figuras regulares planas para o cálculo de áreas de regiões delimitadas por gráficos de funções, no caso, funções de $1^{\circ}$ e $2^{\circ}$ grau. Além disso, conseguiram, com auxílio do recurso computacional, calcular a área da região, limitada, abaixo da curva do gráfico de uma função e acima do eixo OX, através da soma da área de retângulos abaixo e acima da curva, por aproximações sucessivas, de acordo com o aumento do número de retângulos.

\section{Conclusões}

O presente trabalho teve como objetivo avaliar a possibilidade e a necessidade da inserção das noções intuitivas do Cálculo Diferencial e Integral no Ensino Médio, ainda no primeiro ano, aliado ao estudo de funções. Pode-se verificar que ao deixar de trabalhar essas ideias, se perde uma ótima oportunidade de ampliar o conhecimento dos estudantes e de mostrar a aplicação dos conceitos matemáticos que estão presentes no currículo desse ano.

Vimos que as atividades propostas podem ser inseridas dentro do desenvolvimento dos programas de ensino já existentes, adaptando as abordagens aos conteúdos e proporcionando aos estudantes um ensino baseado na experimentação, na visualização e na aplicação dos conceitos estudados. Os problemas geradores do cálculo, ou seja, o problema da velocidade instantânea, o problema da reta tangente e o problema do cálculo da área de regiões limitadas por curvas, que foram abordados no decorrer desse trabalho, puderam ser trabalhados de maneira bastante intuitiva com o auxílio do software GeoGebra.

Além disso, o entendimento e o trabalho com limites, através de processos infinitos de aproximação, aplicado ao estudo de funções pode facilitar o entendimento do comportamento do gráfico de cada tipo de função.

O conceito intuitivo de derivada de uma função em um ponto através da construção e do entendimento do conceito de reta tangente ao gráfico de uma função e da análise do coeficiente angular dessa reta, também foram assuntos entendidos pelos estudantes. Verificou-se que é possível ensinar esse conceito aos estudantes ainda no primeiro ano do Ensino Médio. Além disso, o significado e o cálculo da velocidade instantânea também foram assuntos motivadores para os estudantes, que questionaram e procuraram entender a aplicação desse assunto na prática. 
Em relação ao cálculo da área sob o gráfico de uma função em um intervalo determinado do seu domínio, os estudantes se mostraram bastante interessados, principalmente pelas ferramentas disponíveis no software GeoGebra. Sem dificuldades, conseguiram compreender a ideia de aproximar a área utilizando um número cada vez maior de figuras geométricas conhecidas como retângulos. O processo infinito de aproximação esteve presente nas justificativas dos estudantes, durante todo o processo, de modo que é possível afirmar que eles compreenderam a ideia intuitiva do cálculo da integral definida das funções apresentadas nas atividades para o intervalo considerado em cada caso.

Acredita-se que uma maior atenção à aplicação, à experimentação e a visualização dos conceitos matemáticos nesta fase da escolaridade, pode ajudar a reverter o quadro de dificuldades e os altos índices de reprovação nas disciplinas de Cálculo no Ensino Superior. A disciplina de Cálculo é responsável por um grande número de reprovações e desistências de alunos nos cursos de graduação, uma vez que os mesmos, ao ingressarem em um curso superior nas áreas de Ciências Exatas e de Tecnologia, se deparam com atividades muitas vezes sem contextualização e já aprofundadas, sem este estudo prévio, ou seja, sem a construção das ideias fundamentais para a compreensão da disciplina em questão.

Por essa razão acredita-se que, o que foi proposto se constitui numa estratégia de ensino e aprendizagem que contribui para a melhoria do ensino de Matemática. Tornar a matemática mais fácil e possível de ser compreendida pode ser uma tarefa intimamente ligada à metodologia adotada para se ensinar cada conteúdo. Com certeza, se o professor buscar relacionar os conteúdos com situações reais, que exijam dos estudantes a reflexão e o raciocínio, a partir de contextos que, para ele, façam sentido, um obstáculo das dificuldades em Matemática, já está sendo vencido. Isso já representa um passo em busca da melhoria no rendimento dos estudantes nessa disciplina, seja no Ensino Médio ou Superior.

De fato, a experiência realizada não verifica se os resultados seriam os mesmos para uma turma regular de alunos do Ensino Médio, uma vez que os alunos que formaram a turma experimental aceitaram participar dessa experiência, antecipadamente. Apesar disso, acredita-se que, da mesma forma como esses estudantes se mostraram empolgados e demonstraram interesse nas atividades de aplicação e na utilização do software, os estudantes de uma turma regular podem se mostrar abertos a novas abordagens para os conceitos matemáticos. Além disso, as atividades podem ser selecionadas e exploradas aos poucos durante o estudo de cada uma das funções e demais conteúdos que integram o currículo de matemática do Ensino Médio.

\section{Referências}

ANTON, Howard. Cálculo, um novo horizonte. 6 ed. Porto Alegre: Bookman, 2000. 
ÁVILA, Geraldo. O ensino de Matemática. In: Revista do Professor de Matemática, $\mathrm{n}^{\circ}$ 23. Rio de Janeiro: Sociedade Brasileira de Matemática (SBM), 1993, p. 1-7.

ÁVILA, Geraldo. Limites e Derivadas no Ensino Médio? In: Revista do Professor de Matemática, $\mathrm{n}^{\circ}$ 60. Rio de Janeiro: Sociedade Brasileira de Matemática (SBM), 2006, p. 30-38.

DUCLOS, Robert Costallat. Cálculo do $2^{\circ}$ grau. In: Revista do Professor de Matemática, n.20. Rio de Janeiro, Sociedade Brasileira de Matemática (SBM), 1992, p.26-30.

MACHADO, Nílson José. Cálculo Diferencial e Integral na Escola Básica: possível e necessário. São Paulo: USP, 2008. Disponível em http://www.nilsonmachado.net/sema200 80311.pdf . Acesso em 25 jul. 2012.

REZENDE, Wanderley Moura. O ensino de Cálculo: dificuldades de natureza epistemológica, In: MACHADO, N. ; CUNHA, M. (org). Linguagem, Conhecimento, Ação - ensaios epistemologia e didática. Escrituras: São Paulo, 2003. Disponível em: http://www.nilsonmachado.net/lca19.pd f. Acesso em 18 set. 2012.

SBM. Fundamentos de Cálculo. Material disponibilizado ao PROFMAT, 2012.

SIMÕES, Márcio. Cálculo sem pressa é bom. Cálculo: Matemática para todos. SEGMENTO: São Paulo, ed. 13, ano 2, p. $24-33,2012$. 